\title{
Resistance to ketosis during prolonged fasting by rats fed on a diet containing undecanoic acid, an odd- carbon-number fatty acid
}

\author{
By F. X. PI-SUNYER \\ Department of Medicine and Institute of Human Nutrition, Columbia University College \\ of Physicians and Surgeons, St Luke's Hospital Center, New York, NY 10025, USA
}

(Received I I December I974-Accepted 5 March 1975)

\begin{abstract}
I. Sixty-four male rats were fed on a nutritionally complete diet containing $30 \%$ of the dietary energy as fat. For thirty-two rats (control) the fat source was maize oil; for the remaining thirty-two rats (experimental) the fat source was triundecanoin-maize oil $(7: 3, w / w)$.

2. After 6 weeks, groups of control and experimental rats were fasted and killed on days $0,1,2$ and 4 of the fasting period. In the experimental group, adipose-tissue fatty acids contained, on average, $246 \mathrm{mmol}$ undecanoic acid/mol total fatty acids. In contrast, the adipose tissue of the control group did not contain odd-carbon-number fatty acids.

3. Plasma glucose levels were significantly higher for all fasted experimental groups and blood ketone levels were significantly lower for these groups.

4. Thus, during prolonged starvation, animals which accumulated odd-C-number fatty acids resisted the development of ketosis. It appeared that odd-C-number fatty acids mobilized from fat depots during fasting may provide their terminal three-C residues for gluconeogenesis rather than for acetyl-CoA production, thereby allowing for better maintenance of blood glucose and insulin levels than in control animals.

5. It is concluded that the lower acetyl-CoA production and higher blood insulin levels reduce ketogenesis.
\end{abstract}

The results of previous studies indicate that the proportion of odd-carbon-number, medium-chain fatty acids in the adipose-tissue triglycerides of weanling rats can be substantially increased by prolonged feeding of a diet containing triundecanoin (Shin, I969; Van Itallie \& Khachadurian, 1969). $\beta$-Oxidation of the odd-C-number fatty acids produces propionate which is potentially glucogenic (Deuel, Butts, Hallman \& Cutler, 1935; Butts, Blunden, Goodwin \& Deuel, 1937; Siegel \& Lorber, 1951). Rats fed on diets containing triundecanoin and subsequently fasted are able to maintain blood glucose and immunoreactive insulin and liver glycogen at appreciably higher levels than conventionally fed control rats (Van Itallie \& Khachadurian, 1969; Pi-Sunyer, 1971).

This paper describes a study of the ketonaemic response to fasting of rats whose adipose tissue contained a high proportion of odd-C-number fatty acids compared to rats whose adipose tissue contained a high proportion of even-C-number fatty acids.

\section{MATERIALS AND METHODS}

Sixty-four Sprague-Dawley weanling male rats each weighing approximately $50 \mathrm{~g}$ were used. The rats were divided into two equal groups. Each group was fed on one of two nutritionally complete diets (Wooley \& Sebrell, 1945) containing, as a percentage of dietary energy, 20 protein (casein), $5^{\circ}$ carbohydrate (sucrose), $3 \circ$ fat. 'The fat source 
for experimental animals was triundecanoin-maize oil $(7: 3, w / w)$ and for the control animals it was maize oil. All animals were housed individually, weighed weekly and fed to appetite for 6 weeks.

At the end of the 6-week feeding period, the rats in each of the two groups were weighed and divided into four subgroups each of eight animals. One group was killed at the end of 6 weeks (day o); the other three groups were fasted, with access to water only, for $\mathrm{I}, 2$ and $4 \mathrm{~d}$. At the end of each of these periods of fasting, the groups of rats were anaesthetized by intraperitoneal administration of sodium pentobarbital $(4 \mathrm{mg} / \mathrm{kg}$ body-weight), and blood was then obtained by aortic puncture. Plasma was separated and frozen for subsequent measurement of glucose concentrations, which were determined using an AutoAnalyzer (Technicon Instruments Corporation, Chauncey, New York, USA) and the method of Hoffman (1937). Also, protein-free filtrates of blood were immediately prepared using I $\mathrm{ml}$ trichloroacetic acid solution ( $100 \mathrm{~g} / \mathrm{l}) / \mathrm{ml}$ blood as the protein precipitant.

Acetoacetate contents of the protein-free filtrates were determined spectrophotometrically (Williamson, Mellanby \& Krebs, I962) and their $\beta$-hydroxybutyrate contents were measured fluorimetrically (Young \& Renold, 1966). These ketone-body estimations were done within $3 \mathrm{~d}$ of blood collection. The samples were kept frozen at $-20^{\circ}$ until analysed.

Samples of perirenal adipose tissue were taken from eight of the control rats (two for each period of fasting) and from all experimental rats (those given triundecanoin). Only representative control animals were taken because previously reported results indicated a constancy in the fatty acid pattern during starvation (Van Itallie \& Khachadurian, I969). The adipose tissue was homogenized in chloroform-methanol (C-M) $(2: \mathrm{r}, \mathrm{v} / \mathrm{v})(20 \mathrm{ml} / \mathrm{g}$ tissue). Distilled water, previously equilibrated with $\mathrm{C}-\mathrm{M}$ for $2 \mathrm{~h}$, was added, the tube was shaken thoroughly and the mixture was allowed to stand until two distinct layers had formed. A portion of the C-M layer was taken and evaporated to dryness under nitrogen in a water bath at $40^{\circ}$. The fatty acid composition of the lipid extracted from adipose tissue samples from each rat was determined after transmethylation with sodium methoxide. Methyl esters of fatty acids were analysed by a gas-liquid chromatography system (F \& M 5750; Hewlett-Packard, New York, USA) using a hydrogen flame detector and a $\mathrm{I} .8 \mathrm{~m}$ column containing $\mathrm{I} 20 \mathrm{~g}$ diethylene glycol succinate/kg 80-100 mesh Gas-chrom P (Applied Science Labs, College Park, Pennsylvania, USA). In order to ensure separation of the shorter-chain fatty acid esters, all samples were chromatographed initially at a low temperature $\left(90^{\circ}\right.$ ) and by use of programming at $4 \% \mathrm{~min}$, the temperature was increased to $180^{\circ}$ for elution of the longer-chain fatty acid esters.

Statistical significance of differences between sample means were calculated using Student's $t$ test. Analyses of variance were also done.

\section{RESULTS}

The mean body-weight and SE at the beginning of the experiment was $50.7 \pm 0.5 \mathrm{~g}$ for the control rats and $50.9 \pm 0.5 \mathrm{~g}$ for the experimental rats (those given 
Table I. Fatty acid composition (mmol/mol total fatty acid) of perirenal adipose tissue from rats after 6 weeks of feeding on a diet* containing triundecanoin-maize oil (7:3, $w / w)$ as the dietary fat source (experimental) compared to that of rats fed on a diet* containing maize oil as the fat source (control)

(Mean values with their standard errors for thirty-two rats for the experimental group and eight rats† for the control group)

tr, Trace.

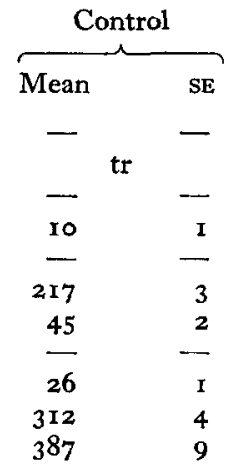

\begin{tabular}{|c|c|}
\hline Expe & \\
\hline Mean & SE \\
\hline 246 & 5 \\
\hline IO & I \\
\hline 12 & I \\
\hline $\begin{array}{r}\mathrm{I} 4 \\
8\end{array}$ & I \\
\hline 219 & 7 \\
\hline $3^{8}$ & 2 \\
\hline $\mathbf{I}$ & 0 \\
\hline 39 & 2 \\
\hline 253 & 6 \\
\hline I 57 & 4 \\
\hline
\end{tabular}

* For details of diets, see p. 4I.

+ A representative sample of control animals was taken because previously reported results indicated a constancy in the fatty acid pattern during starvation (Van Itallie \& Khachadurian, 1969).

Table 2. The effect of different periods of fasting on plasma glucose concentrations (mmol/l) for rats fed for 6 weeks on a diet $\dagger$ containing triundecanoin-maize oil $(7: 3$, w/w) as the dietary fat source (experimental) compared to those for rats on a diet containing maize oil as the fat source (control)

(Mean values for eight rats/treatment)

Period of fasting

Control
$8 \cdot 09$
$6 \cdot 49$
$5 \cdot 23$
$5 \cdot 77$

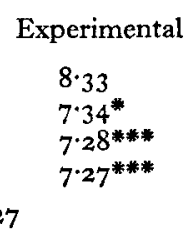

Values for the experimental group were significantly different from those for the control group: * $P<0.05$, *** $P<0.001$.

$\uparrow$ For details of diets, see p. 4 I.

triundecanoin). After the 6-week feeding period, the mean body-weights of the two groups did not differ significantly (control rats $262 \cdot 3 \pm 4 \cdot 3 \mathrm{~g}$, experimental rats $254 \cdot 9 \pm$ $4 \cdot \mathrm{g})$.

There was no statistically significant difference in weight loss between the fasted rats from the control and experimental groups. The mean weight losses and SE were respectively $(\mathrm{g})$ : day $\mathrm{I} I 7 \cdot 3 \pm \mathrm{I} \cdot 3,19 \cdot 2 \pm \mathrm{I} \cdot 0$; day $227 \cdot 0 \pm \mathrm{I} \cdot 0,26 \cdot 6 \pm 2 \cdot 3$; day 4 $51 \cdot 8 \pm 5^{\cdot 1}, 49 \cdot 4 \pm 2 \cdot 9$.

The adipose-tissue fatty acid patterns for the two groups of rats after the 6-week feeding period with the two diets are given in Table I. Undecanoic acid comprised 
Table 3. The effect of different periods of fasting on blood ketone-body concentrations (mmol/l) for rats fed for 6 weeks on a diet $\uparrow$ containing triundecanoin-maize oil $(7: 3, w / w)$ as the dietary fat source (experimental) compared to those for rats fed on a diet containing maize oil as the fat source (control)

(Mean values for eight rats/treatment)

\begin{tabular}{|c|c|c|c|c|c|c|}
\hline \multirow{2}{*}{$\begin{array}{l}\text { Period of } \\
\text { fasting } \\
\text { (d) }\end{array}$} & \multicolumn{2}{|c|}{ Acetoacetate } & \multicolumn{2}{|c|}{$\beta$-Hydroxybutyrate } & \multicolumn{2}{|c|}{$\begin{array}{c}\text { Total ketones (acetoacetate } \\
+\beta \text {-hydroxybutyrate) }\end{array}$} \\
\hline & Control & Experimental & Control & Experimental & Control & Experimental \\
\hline 0 & 0.160 & 0.203 & 0.238 & 0.116 & 0.398 & 0.319 \\
\hline $\mathbf{I}$ & 0.385 & $0.197^{* * * *}$ & 0.758 & $0.337^{* * * *}$ & $I \cdot 143$ & $0.534^{* * *}$ \\
\hline 2 & 0.412 & $0.237^{*}$ & $1 \cdot 348$ & $0.659^{* *}$ & $x \cdot 760$ & $0.896 * *$ \\
\hline \multirow[t]{2}{*}{4} & 0.259 & $0.175^{* * *}$ & 0.969 & $0.328 * * *$ & $I \cdot 228$ & $0.503^{* * * *}$ \\
\hline & \multicolumn{2}{|c|}{$S E \pm 0.034$} & \multicolumn{2}{|c|}{ SE \pm 0.094} & \multicolumn{2}{|c|}{$S E \pm 0.123$} \\
\hline
\end{tabular}

Values for the experimental group were significantly different from those for the control group: * $P<0.05$, ** $P<0.01$, ,** $P<0.001$.

$\dagger$ For details of diets, see p. $4 \mathrm{r}$.

$246 \mathrm{mmol} / \mathrm{mol}$ total adipose-tissue fatty acids for the rats given triundecanoin. Smaller amounts of $\mathrm{C}_{13}, \mathrm{C}_{15}$ and $\mathrm{C}_{17}$ fatty acids were found, giving a total of $267 \mathrm{mmol}$ odd-Cnumber fatty acids/mol total fatty acids. Adipose tissue from the control rats contained only even-C-number fatty acids, with a relatively high proportion of linoleate (I8:2), reflecting their intake of maize oil.

The effect of different periods of starvation on plasma glucose concentrations is shown in Table 2. Although on day o of the fasting period both groups of animals had similar plasma glucose concentrations, throughout the fasting period the glucose concentrations were significantly higher for the experimental group than for the control group.

Values for blood acetoacetate and $\beta$-hydroxybutyrate concentrations are given in Table 3. Blood acetoacetate and $\beta$-hydroxybutyrate concentrations were similar for both groups on day $\circ$ of the fasting period. During the fasting period the acetoacetate concentration increased for both groups, but the increase was significantly lower for the experimental group throughout this period. $\beta$-Hydroxybutyrate concentrations also increased for both groups during fasting and the increase was significantly lower for the experimental group throughout this period of starvation. The total blood ketone-body concentrations ( $\beta$-hydroxybutyrate + acetoacetate) also are given in Table 3. Although values for both groups were comparable on day o of the fasting period, total ketone-body concentrations were significantly lower for the experimental groups throughout the period of starvation.

\section{DISCUSSION}

During fasting, free fatty acids are mobilized from adipose tissue in increasing quantities and are utilized by the liver and other tissues. For rats given diets containing triundecanoin, odd-C-number fatty acids are mobilized readily, but not preferentially, from adipose tissue (Van Itallie \& Khachadurian, I969), and together with even-C- 
number fatty acids undergo $\beta$-oxidation by a similar pathway to that of even-C-number fatty acids, except that the final thiolytic cleavage produces propionyl-CoA rather than acetyl-CoA. These terminal three-C units are potentially glucogenic; propionyl-CoA is converted to methylmalonyl-CoA then succinyl-CoA (Mazumder, Sasakawa \& Ochoa, I963; Cannata, Focesi, Mazumder, Warner \& Ochoa, 1965). The succinate is readily converted into glucose and glycogen. During starvation, rats given diets containing triundecanoin maintain higher liver glycogen and serum glucose concentrations than do maize-oil-fed, control rats (Van Itallie \& Khachadurian, 1969; Pi-Sunyer, r97I). It is suggested that the terminal three-C units provide enough available carbohydrate for fasted animals to counteract both the depletion of glycogen in the liver and the reduction in blood glucose concentration which are characteristic of starvation.

The results of the present study indicated that there was markedly less ketosis during starvation in rats given triundecanoin in their diet than in control animals. This is consistent with the results of earlier short-term studies in which a decreased production of ketone bodies was found for rats given odd- compared to even-C-number fatty acids (Jowett \& Quastel, I935; Deuel, Hallman, Butts \& Murray, 1936). The smaller ketogenic potential of odd- compared to even-C-number fatty acids has been found also in vitro in studies using liver preparations from both rabbit (Cheldelin \& Beinert, 1952) and rat (Witter, Cottone \& Stotz, 1954). Thus, odd-C-number fatty acids metabolized in the liver produce lower levels of ketone bodies than do comparable molar concentrations of even-C-number fatty acids.

It is considered that the production of propionyl-CoA by the oxidation of odd-Cnumber fatty acids is responsible for the reduced ketogenesis in animals fed on diets containing odd-C-number fatty acids. Therefore, during starvation when undecanoic acid is mobilized from adipose stores in rats given triundecanoin in their diet, ketonebody production will be lower than in control rats mobilizing only even-C-number fatty acids.

Also important in the reduced ketosis of the triundecanoin-fed rat is the level of circulating insulin. Insulin is a primary regulator of ketogenesis. In the ketotic animal, there is a relative or absolute deficiency of insulin, and both the ketosis of starvation (Foster, 1967) and of diabetes (Chernick \& Scow, 1959) can be reversed rapidly with insulin. The results of previous studies have indicated that triundecanoin-fed rats have significantly higher circulating insulin levels during starvation (Pi-Sunyer, 1971; Kim \& Pi-Sunyer, 1974). This is attributable to the maintenance of higher blood glucose levels in these animals during fasting. For the animals in the present study, the higher blood glucose and insulin levels found would, presumably, inhibit ketogenesis.

Hyperketonaemia in both groups of rats reached its peak on the second day of fasting, decreasing thereafter. A similar decrease in ketosis in rats as starvation progresses has been reported by Parilla, Toews \& Cahill (r971), who found that the rat, unlike man, fails to conserve $\mathrm{N}$ during starvation. Gluconeogenesis is not reduced as it is in man, but rather increases progressively with continued fasting. This gradual increase is thought to occur because the rat has more energy in its muscle protein than in its limited adipose tissue reserve (Cahill, Aoki \& Ruderman, r973). As fat stores 
are rapidly depleted in prolonged fasting, the amount of free fatty acids which reaches the liver decreases, ketone-body production is reduced and blood ketone-body concentrations decrease (Cahill et al. I973).

The plasma glucose concentration for the control group reached its lowest values on the second day of fasting and subsequently increased again, but not to prefasting levels. This phenomenon has been described previously (Hershey \& Orr, 1928; Pi-Sunyer, 197I) and is probably the result of increased gluconeogenesis and decreased glucose utilization by the peripheral tissues during prolonged fasting. That no similar pattern in blood glucose concentrations was obtained for triundecanoin-fed rats is attributable to further gluconeogenesis from undecanonate-derived propionate (Van Itallie \& Khachadurian, I969; Pi-Sunyer, I97I).

This work was supported in part by grant AM-I 7624 from the National Institutes of Health, USA. The technical help of Mrs Marsha Cheng and Miss Ellen Greenebaum is gratefully acknowledged.

\section{REFERENCES}

Butts, J. S., Blunden, H., Goodwin, W. \& Deuel, H. J. Jr (1937). F. biol. Chem. II7, I3I.

Cahill, G. F. Jr, Aoki, T. T. \& Ruderman, N. B. (1973). Trans. Am. clin. clim. Ass. 84 , I84.

Cannata, J. J. B., Focesi, A. Jr, Mazumder, R., Warner, R. C. \& Ochoa, S. (1965).J. biol. Chem. 240, 3249.

Cheldelin, V. H. \& Beinert, H. (r952). Biochim. biophys. Acta 9, 66r.

Chernick, S. S. \& Scow, R. O. (1959). Am. F. Physiol. 196, r25.

Deuel, H. J. Jr, Butts, J. S., Hallman, L. F. \& Cutler, C. H. (1935). F. biol. Chem. rra, 5.

Deuel, H. J. Jr, Hallman, L. F., Butts, J. S. \& Murray, S. (1936). F. biol. Chem. rr6, 6ar.

Foster, D. W. (1967). F. clin. Invest. 46, 1283.

Hershey, J. M. \& Orr, M. D. (1928). Trans. R. Soc. Can. Sect. 5, 22, I5I.

Hoffman, W. S. (1937). F. biol. Chem. 120, 5 I.

Jowett, M. \& Quastel, J. H. (I935). Biochem. F. 29, 2 I 59.

Kim, S. \& Pi-Sunyer, F. X. (1974). Diabetes 23, 605.

Mazumder, R., Sasakawa, T. \& Ochoa, S. (1963). F. biol. Chem. 238, 50.

Parilla, R., Toews, C. S. \& Cahill, G. F. Jr (1971). Proc. 53 rd a. Meet. Endocr. Soc. p. A57.

Pi-Sunyer, F. X. (197I). Diabetes 20, 200.

Shin, M. S. (1969). Nutrition and metabolic studies of a medium chain odd-numbered triglyceride PhD Thesis, Columbia University, New York.

Siegel, I. \& Lorber, Y. (195 I). F. biol. Chem. 189, 57 I.

Van Itallie, T. B. \& Khachadurian, A. K. (rg69). Science, N. Y. 165, 8 I r.

Williamson, D. H., Mellanby, J. \& Krebs, H. A. (1962). Biochem. J. 82, 90.

Witter, R. F., Cottone, M. A. \& Stotz, E. (1954).F. biol. Chem. 207,671.

Wooley, J. G. \& Sebrell, W. H. (1945). F. Nutr. 29, I9I.

Young, D. A. B. \& Renold, A. E. (1966). Clinica chim. Acta r3, 791. 